\title{
Para la génesis de Gurka (un frío como el agua, seco), de Vicente Zito Lema: periodismo y dramaturgia liminalizados por la Antropología Teatral Poética ${ }^{1}$
}

\author{
Ricardo Adrián Dubatti \\ CONICET / Universidad de Buenos Aires \\ ricardo.dubatti@gmail.com
}

\begin{abstract}
Resumen
En el teatro argentino de postdictadura abundan las representaciones de la Guerra de Malvinas, enfrentamiento con el Reino Unido que tuvo lugar del 2 de abril al 14 de junio de 1982. En dicho corpus sobresale Gurka (un frío como el agua, seco), de Vicente Zito Lema, estrenada en noviembre de 1988 y vuelta a representar en numerosas ocasiones. Desde la crítica genética y la poética comparada se estudian la relación entre el texto dramático y su antecedente periodístico, "Las Malvinas en el hospicio. 'Un frío como el agua, seco'”, publicado en abril del mismo año, y la deliberada conexión liminal entre entrevista, teatro y "Antropología Teatral Poética" propuesta por Zito Lema.
\end{abstract}

\section{Palabras clave}

Teatro; periodismo; antropología; crítica genética; poética comparada.

\section{Para a genese de Gurka (un frío como el agua, seco), de Vicente Zito Lema:} jornalismo e dramaturgia em liminalidade com a Antropología Teatral Poética

\begin{abstract}
Resumo
No teatro argentino da postdictadura abundam representações da Guerra das Malvinas, confronto com o Reino Unido no período de 2 de abril a 14 de junho de 1982. Neste corpus destaca-se Gurka (un frío como el agua, seco), de Vicente Zito Lema, estreado em novembro de 1988 e novamente representado em várias ocasiões. A partir da crítica genética e da poética comparativa, estuda-se a relação entre o texto dramático e seu antecedente jornalístico "Las Malvinas en el hospicio. 'Un frío como el agua, seco'" (Fin de Siglo, abril 1988) e a conexão liminar deliberada entre entrevista, teatro e "Antropologia Teatral Poética" proposta por Zito Lema.
\end{abstract}

\section{Palavras-chave}

Teatro; jornalismo; antropologia; crítica genética; poética comparativa; liminalidade.

For the genesis of Gurka (un frío como el agua, seco) by Vicente Zito Lema: journalism and theater liminalized by Poetic Theatrical Anthropology

\begin{abstract}
In Argentina's post-dictatorship theater, we find many representations of the Falklands War, a confrontation with the United Kingdom that took place from April 2 to
\end{abstract}

Beca doctoral CONICET "Representaciones de la Guerra de Malvinas (1982) y sus consecuencias socioculturales en el teatro argentino (1982-2017): poéticas dramáticas, historia y memoria". Bajo la dirección de Hugo Mancuso y la codirección de Mauricio Tossi. 
June 14, 1982. In this corpus, Vicente Zito Lema's Gurka (un frío como el agua, seco) is a prominent play that was first performed in November of 1988 and restaged numerous times since then. Using genetic criticism and comparative poetics, we study the relationship between the dramatic text and its journalistic antecedent, "Las Malvinas en el hospicio. 'Un frío como el agua, seco,'”, published in April of the same year, and the deliberate liminal connection between interview, theater, and "Poetic Theatrical Anthropology".

\section{Keywords}

Theater; journalism; anthropology; genetic criticism; comparative poetics. 
Pero por cada cien pretendidas patogenias (...), ¿̇uántas nobles tentativas se han hecho para acercarse al mundo cerebral en el que viven aquellos que ustedes han encerrado? ¿Cuántos de ustedes, por ejemplo, consideran que el sueño del demente precoz o las imágenes que lo acosan son algo más que una ensalada de palabras.

Antonin Artaud, "Carta a los directores de los asilos de locos" (1988)

En el marco de la investigación sobre el corpus de representaciones de la Guerra de Malvinas ${ }^{2}$ en el teatro argentino, el texto dramático Gurka (un frío como el agua, seco), de Vicente Zito Lema ${ }^{3}$, tiene una relevancia central, ya que es el que ha merecido mayor cantidad de puestas en escena desde su estreno, en $1988^{4}$. Es necesario contextualizarlo entre más de cincuenta obras teatrales que, escritas y escenificadas en los últimos 35 años (R. Dubatti, 2017a: 16-20) , $^{5}$ cumplen en la postdictadura una función memorialista sobre la Guerra de Malvinas. Nueva etapa cultural de la Argentina iniciada en 1983, tras el fin del gobierno de facto por la restitución de la democracia (Cattaruzza, 2012: 82-83) ${ }^{6}$, la postdictadura otorga al prefijo "post-" un doble sentido: lo que viene después de la dictadura; lo que ocurre como consecuencia de la dictadura. A 35 años del enfrentamiento bélico, resulta conflictivo formular una interpretación histórica orgánica y conclusiva sobre un hecho que los investigadores califican de "dilemático" (Rozitchner, 2015: 75-76). La guerra, como señala Bernard McGuirk ya desde el título de su libro, pervive hoy como un "asunto inconcluso" (2007).

El teatro de postdictadura revela que los procesos de violencia institucional sistematizados por la dictadura a partir del golpe cívico-militar de 1976 continúan

\footnotetext{
La Guerra de Malvinas consistió en un enfrentamiento bélico entre Argentina y el Reino Unido ocurrido en 1982. Impulsada por el gobierno de facto (1976-1983), duró 74 días, desde el 2 de abril al 14 de junio.

3 La intensa actividad de Vicente Zito Lema (Buenos Aires, 14 de noviembre de 1939) cruza la dramaturgia, la abogacía, el periodismo y la docencia, transversalizadas por la política. Como abogado (desde 1961) se especializa en la teoría y la práctica de los Derechos Humanos. Fue discípulo de Enrique Pichon-Rivière (impulsor de la psicología social), con quien fundó la primera cátedra sobre mecanismos de la creación artística en la Facultad de Filosofía y Letras de la Universidad de Buenos Aires. Frecuentó al poeta Jacobo Fijman, de intensa presencia intertextual en los escritos de Zito Lema. Perseguido por la dictadura, en 1977 se exilió en Holanda. Durante el exilio formó parte de la Comisión Argentina de Derechos Humanos (CADHU), junto a Julio Cortázar, Eduardo Luis Duhalde y David Viñas, entre otros. Desde su retorno a la Argentina en 1984, retomó su tarea periodística y dirigió las revistas Fin de Siglo, Locas y La Maga. En 2000 integró el equipo fundador de la Universidad Popular Madres de Plaza de Mayo, de la que fue rector (2000-2003). Es autor de una amplia producción dramática, reunida en los volúmenes Delirium Teatro. Obra teatral completa (1999), Lengua sucia: escenas de poder, servidumbre y muerte (2000) y los dos tomos de Todo es Teatro. Obra completa 1970-2015 (2015a; 2015b).
}

4 Gurka (un frío como el agua, seco) se estrenó en Buenos Aires en noviembre de 1988, en el Teatro Calibán, con dirección de Norman Briski y actuación de Ricardo Miguélez e integrantes del Frente de Artistas del Hospital Borda.

5 Para un primer listado cronológico, véase "Prólogo. La Guerra de Malvinas en el teatro, el teatro de la guerra" (R. Dubatti, 2017a: 16-20).

6 Sobre la noción de postdictadura en su relación con las artes escénicas, véase Jorge Dubatti (2012: 203-252). 
presentes hasta la actualidad porque, como afirma Giorgio Agamben sobre Auschwitz (2000: 15), nunca han dejado de acontecer. El teatro contribuye a la producción de memorias colectivas que recuperan los hechos traumáticos del pasado reciente para no olvidar el pasado y para que esos acontecimientos no se multipliquen en el futuro, al mismo tiempo que propicia lecturas del presente. Teatro y memoria, como acontecimientos de la cultura viviente, son fenómenos territoriales radicantes (Bourriaud, 2009); se arraigan en coordenadas socioculturales concretas y son parte de una constante transformación social. El teatro construye poéticas que adquieren el valor de metáforas epistemológicas ${ }^{7}$. La poíesis corporal del teatro permite evocar acontecimientos de la historia reciente y, a la vez, posibilita la producción de nuevos sentidos. En la postdictadura, el teatro se ofrece como un terreno estimulante para la concretización de representaciones que dan expresión a aquello que se manifiesta como conflictivo (Chartier, 1992: 52-52). Puede así manifestar lo "no decible" (Mancuso, 2010: 226-227), en tanto activa "los trabajos de la memoria" (Jelin, 2002: 37).

En este contexto, el presente artículo examina el caso de Gurka (un frío como el agua, seco) $)^{8}$ con el objetivo de analizar su génesis o proceso de escritura en tanto relevante para la comprensión de su poética. Gurka tiene como antecedente la nota periodística "Las Malvinas en el hospicio. 'Un frío como el agua, seco"” (1988), aspecto no estudiado hasta hoy. Su génesis vincula periodismo y teatro a través del proyecto estético-político de una "Antropología Teatral Poética" (ATP) explicitado sistemáticamente por su autor. Para Zito Lema, periodismo, teatro y poesía tienen un vínculo liminal, fronteras borrosas y fusiones, formando aquello que, en palabras de lleana Diéguez Caballero, es un "espacio donde se configuran múltiples arquitectónicas, una zona compleja donde se cruzan la vida y el arte, la condición ética y la creación estética, como acción de la presencia de un medio de prácticas representacionales" (2007: 16). Zito Lema construye un continuum discursivo con zonas de cruce e hibridación de géneros donde, deliberadamente, no es posible diferenciar con nitidez cada territorio genérico. El título elegido por el autor para la edición de los dos tomos de su dramaturgia completa (2015a; 2015b), "Todo es teatro", explicita ese continuum visto desde el ángulo teatral. Zito Lema formula una ATP para dar entidad estético-política a esa desdelimitación. Su dramaturgia busca un estatus liminal ${ }^{9}$. Para el análisis de Gurka,

\footnotetext{
7 Umberto Eco define: "El arte, más que conocer el mundo, produce complementos del mundo, formas autónomas que se añaden a las existentes exhibiendo leyes propias y vida personal. No obstante, toda forma artística puede muy bien verse, si no como sustituto del conocimiento científico, como 'metáfora epistemológica', es decir, en cada siglo el modo de estructurar las formas del arte refleja -a guisa de semejanza, de metaforización, de apunte de resolución del concepto en figura- el modo como la ciencia o, sin más, la cultura de la época ven la realidad" (1984: 88-89).

8 En adelante, Gurka.

9 Además del libro de Diéguez Caballero (2007), específicamente sobre el concepto de teatro liminal, seguimos a Jorge Dubatti (2016).
} 
recurriremos a bases teóricas y metodológicas de la crítica genética ${ }^{10}$ y la poética comparada ${ }^{11}$ que, por razones de extensión, sólo explicitaremos brevemente.

\section{Gurka, el excombatiente en el hospicio}

Bajo la forma del soliloquio o del monólogo (el texto es ambiguo al respecto: nunca sabremos con precisión si el personaje habla solo, si piensa y se proyecta en escena su voz interna o si está hablando a un interlocutor elidido escénicamente) $)^{12}$, la obra se construye en la voz de un personaje obsesionado por los gurkas-soldados de Nepal que combatían para la corona británica desde 1816, registrados en numerosos testimonios de la guerra de Malvinas como máquinas de matar (véase, por ejemplo, Kon, 1982) y rodeados de un fuerte aire mítico, especialmente debido a su presunto sadismo-. Poco a poco, reconocemos esta voz como la de un paciente-interno joven de un hospital psiquiátrico ${ }^{13}$. El personaje no tiene nombre y no hay didascalias iniciales de ubicación espacial ni temporal. Por la deriva del discurso del personaje, por la sucesión y enlace de las imágenes que refiere, la estructura dramática presenta una compleja causalidad interna.

La situación que abre el texto dramático remite al relato de sueños-pesadillas. Tras narrar dos episodios oníricos y declarar que escucha una voz "que me habla" (1999: 14), el personaje hace una primera referencia específica a coordenadas deícticas de espacio y tiempo: se confronta la lejanía de "las islas" con la cercanía del "aquí, con los medicamentos" (14). Los sueños se manifiestan significativos, ya que la voz otra afirma que son ideales para auto-conocerse, al mismo tiempo que "ponen en peligro" la vida de quien los cuenta (14). Sigue el relato de dos nuevos sueños-pesadillas en los que aparece la violencia como amenaza constante, mediante imágenes de violación y una "mano enguantada" que sale del espejo del baño con un cuchillo (15). Quien habla comenta no saber por qué está internado, pero refiere un ambiguo hecho de su prehistoria: ha sufrido un accidente en el Hospital Ferroviario. "Al pasar por el molinete de aire las puertas giratorias me

\footnotetext{
10 La crítica genética focaliza el estudio de los mecanismos de la creatividad textual, considerados como su instancia de producción. Este proceso se completa luego con las teorías del texto y los estudios de la recepción (Lois, 2001). Según Almuth Grésillon, "la crítica genética ha definido progresivamente su objeto propio: los manuscritos de trabajo de los escritores en tanto que soporte material, espacio de inscripción y lugar de la memoria de las obras in statu nascendi; donde se desarrollan sus métodos y finalidades" (1994: 1; la traducción es nuestra).

11 Derivada del teatro comparado, la poética comparada propone el análisis de las poéticas teatrales consideradas en su territorialidad (por relación y contraste con otros fenómenos teatrales territoriales), interterritorialidad y supraterritorialidad. Toda poética se desplaza entre lo universal y lo particular, entre lo abstracto y lo interno, entre lo general y lo concreto, "entre lo uno y lo diverso" (Guillén, 1985), entre territorialidades múltiples. Esto permite discernir diferentes tipos de poéticas según el grado de abstracción y de participación de sus rasgos (véanse J. Dubatti, 2009; 2016).

12 Sobre el estatus de indefinición entre soliloquio y monólogo en Gurka, véase Ricardo Dubatti (2017b).

13 Todas las citas de Gurka se hacen por la edición de Delirium teatro (1999: 13-24).
} 
golpearon la mente. Me vino una convulsión, no una epilepsia, algo parecido... ¡Yo no soy ningún epiléptico!" (15). Describe las condiciones de vida de los internos en el hospital: los medicamentos, el trabajo que les obligan a hacer para cuidar a otros enfermos y la poca higiene del lugar. Ya avanzada la pieza, el personaje se autodefine excombatiente, momento en el que comienza el desarrollo propiamente dicho de la intriga: "Yo combatí en las islas, soy un héroe. Nadie me lo perdona. Mis compatriotas me mandaron al hospicio y los gurkas juraron matarme. (...) De día se disfrazan de cualquier cosa, hasta de médicos o enfermeros" (16). Comenta sobre sus expectativas para el momento de salir-tocar la trompeta, conseguir un trabajo- y retorna obsesivamente a la amenaza y persecución de los gurkas. Narra las violaciones que estos realizaban con su cuchillo y remarca haberse escapado de ellos. Evoca a un excombatiente que se suicida con su uniforme puesto y continúa describiendo a los gurkas. Inmediatamente procede a narrar su llegada a "las islas" y sus vivencias allí: cómo le dieron armas sin enseñarle a usarlas, las inyecciones para el frío, la vida en los pozos de zorro, las heridas de guerra.

De pronto, el personaje empieza a narrar como un presentador de boxeo, hecho que a su vez enlaza con el relato de los cowboys Shane y Nevada (19). Ofrece nueva información, siempre ambigua, sobre su vida anterior a la internación y su existencia actual: que practicó boxeo y artes marciales, que se pelea con otros internos y que rescató a dos mujeres carbonizadas del hospital femenino, cuando se incendió. Tras narrar un nuevo sueño, señala que se crio en un instituto de menores (19), que la vida allí era parecida a la del ejército y el hospital y que su madre lo abandonó cuando era niño (20). Enlaza estos recuerdos con las islas y el momento de la rendición. Una vez más, las instituciones (reformatorio, ejército y hospital) y los gurkas aparecen asociados. Revela más datos sobre su vida: cursó hasta sexto grado, por lo que considera que tiene más formación que sus compañeros - "Yo leo mucho, ihasta poesía!" (22). Señala que lo había adoptado una familia, pero que finalmente lo echaron porque "estaba la hija, que andaba siempre en bombacha. iFue ella quien empezó todo! ¡Sí, fuiste vos! ¡Querías bañarte conmigo!" (22). Luego, narra el ingreso de "un hombre medio desnudo (...) atado con una soga gruesa desde la cabeza hasta las piernas (...) Los gurkas lo pisaban con sus botas, le pegaban con sus bastones, él lloraba, ellos le decían: ihacete el loco! ihacete el loco!" (22, bastardilla en el original). Este hecho se asocia con los pozos de zorro y con el Hospicio de las Mercedes - por primera vez menciona así al hospital, con el antiguo nombre del Hospital Borda ${ }^{14}$. Finalmente, el interno refiere diversas situaciones de la guerra, entre ellas el contraste entre el hambre de los soldados y los depósitos llenos de comida, así como los tratos crueles por parte de los oficiales. A su vez, recuerda que vio a un gurka acostarse con un oficial y que ambos lo invitaron a participar de la relación sexual (23). Este último relato promueve una síntesis: sugiere que sus problemas se deben a la inequidad

14 El actual Hospital Municipal José Tiburcio Borda fue conocido como Hospicio de las Mercedes entre 1888 y 1967. 
social y que por eso mató a un oficial argentino al grito de "iGurka! iGurka!" (24, bastardilla en el original).

En una clasificación interna de la producción teatral de Zito Lema, Gurka puede ser incluida en una macropoética de los soliloquios/monólogos. También, desde un eje tematológico, en una macropoética de los textos que forman un "friso" (Weil, 1961: 7) sobre la vida dentro de los manicomios y que presentan las voces de internos, junto a Locas por Gardel (1976), Oratorio Mater (1981), El bronce que sonríe (1996), La piel del otro (1999), Delirium Vida (1999) y Una carretilla de música (1999), incluidos en las obras completas del dramaturgo (2015a; 2015b). Gurka posee además ciertos rasgos constantes en la producción de Zito Lema: el uso de un lenguaje poético que cruza lo elevado y lo bajo, utilizando regularmente expresiones soeces para la manifestación de afirmaciones reveladoras; los sueños como clave significativa tanto de la vida psíquica como de la existencia humana completa; la figura del visitante-testigo (en Gurka probablemente elidida) que trae una mirada desde afuera, asociada con la labor "antropológica" del autor; la recurrencia de ciertas imágenes y frases, como "con este cuchillo te te matamo", la violación masculina y la aparición de Jesucristo; la laicización de referencias cristianas para construir una ambigua hierofanía desde la locura; la configuración de imaginarios del hospicio, con particular interés en el Hospital Borda; las referencias a estructuras musicales. Se advierte en Zito Lema una marcada intratextualidad (-el proceso intertextual [que] opera sobre textos del mismo autor" (Martínez Fernández, 2001: 151). La lectura interconectada de sus obras articula la pieza Una carretilla de música, donde todos los personajes de Delirium Teatro aparecen vinculados, de manera implícita o explícita, en un mismo escenario. Allí se encuentra Marte, personaje obsesionado con los gurkas. Si bien Marte no es necesariamente el personaje de Gurka, en su discurso está presente la asociación entre gurkas y representantes del poder institucional.

\section{"Las Malvinas en el hospicio": una entrevista liminal}

Tanto en el metatexto "Notas sobre el trabajo", incluido en Delirium Teatro (1999: 11-12), como en el volumen primero de Todo es Teatro (2015a: 56), Zito Lema se preocupa por informar que Gurka tiene su origen en una serie de entrevistas que realizó a Miguel ${ }^{15}$, ex combatiente de la Guerra de Malvinas internado en el Hospital Borda "desde 1982" (1999: 11). Allí señala, como antecedente textual del drama, la nota periodística "Las Malvinas en el hospicio: 'Un frío como el agua, seco'”, publicada en la revista Fin de Siglo (1988: 12-15), donde incluyó parte de aquellas entrevistas. Dicha nota no fue reeditada. ¿Por qué pone Zito Lema el acento en su carácter precursor? Porque le interesa dejar manifiesto el continuum de sus prácticas escriturarias.

15 En ninguno de los textos consigna el apellido. 
La nota periodística es una primera escritura de la pieza teatral. En términos de crítica genética, es a la vez pretexto (primera versión germinal) y paratexto (texto autónomo y diverso, que acompaña desde otra zona de producción). Está construida a partir del relato de tres encuentros ${ }^{16}$, en los cuales el periodista Zito Lema dialoga con "el muchacho" (1988: 12). En el reportaje no se explicita el nombre del entrevistado. Tanto en las instancias de diálogo como en los momentos de reflexión solitaria, el entrevistador incorpora su fuerte impronta subjetiva y poética.

De acuerdo con las reglas discursivas de la entrevista periodística cultural (Rivera, 1995: 126-132), transversalizada en Zito Lema por la indagación de la psicología social y la mirada política, en el primer encuentro se realiza una presentación descriptiva del entrevistado. A su vez, se aportan datos del contexto de la entrevista, un "hospicio" (1988: 12) -no se identifica explícitamente al Hospital Borda y recién hacia el final se hace referencia al Hospicio de las Mercedes (15). El entrevistador quiere que el entrevistado le hable de sus sueños: "[El muchacho] no recordaba lo soñado la noche anterior. Tenía otro sueño, sin embargo, que lo seguía desde hace años como un perro y se empeñó en contarlo. Lo alenté, pensando que mi madre andaba en razón: nada mejor que los sueños, aunque sean viejos, para conocer a la gente" (12). Zito Lema pone en crisis el pacto referencial de la entrevista por asimilación de las voces del entrevistado y el entrevistador: "El muchacho con ojos de gato sorbe el aire a grandes bocanadas, como si al contar el sueño se jugara la vida. No sabe que soy incapaz de dar testimonio fiel de lo que escucho; que cuando habla yo hablo con él" (12). Zito Lema sugiere estar reelaborando el testimonio en materia poética-ficcional, estableciendo así una tensión liminal entre ficción y no-ficción. El joven comenta la diferencia entre estar en la guerra de Malvinas y en el hospicio y coloca el énfasis en la distancia, entre un "allá" y un "aquí" (12). Zito Lema profundiza la puesta en suspenso del pacto de referencialidad testimonial: "Hace un año que está internado; aún no sé muy bien las causas." (12). Nos surgen interrogantes: ¿cuándo se hizo la entrevista? ¿En 1988 o en 1983, a seis o un año de la guerra? Por otra parte, los sueños del entrevistado y los del entrevistador comienzan a indiferenciarse. La conversación vuelve a virar hacia las islas: "Yo combati en las Malvinas y fui un héroe. Nadie me lo perdona. Mis compañeros me mandaron a un hospicio y los gurkas juraron matarme. Esperan el momento, me vigilan" (12-13).

La segunda unidad de fragmentación comienza con el relato de un sueño-pesadilla de Zito Lema. Tras Ilegar al hospital, es el interno quien narra su sueño. El entrevistador cambia de tema y pregunta por los motivos de la internación. El joven relata un extraño accidente en el "hospital ferroviario" y agrega que "como no tengo obra social ni nada de eso, me trajeron a este hospital" (13). El entrevistador pregunta acerca del hospicio. El muchacho describe las malas condiciones de la

\footnotetext{
16 Para describir e interpretar las características del artículo periodístico, tomaremos esos tres encuentros como una segmentación interna en tres unidades sucesivas.
} 
institución y cómo, en ocasiones, los propios internos deben encargarse de otros pacientes en peor estado. También habla de "la máquina" -sobre la que no se explicita ningún dato más allá de que la encienden durante la noche- (13). A su vez, cuenta su plan de conseguir un trabajo afuera y vuelve a mencionar a los gurkas. Afirma que se encuentra con otros excombatientes y que "[h]ay mucha violencia, en cualquier momento esto puede ser como en las Malvinas" (13). Luego retoma: "Los gurkas eran bestias gigantes, con trajes térmicos, con cuchillos enormes, con catalejos infrarrojos y fusiles con rayo láser que quemaban el cuerpo, lo que tocaban, hasta las piedras" (13). El joven cuenta que no recuerda cómo llegó a las islas, pero que le proveyeron numerosas armas e inyecciones (13-14). Refiere lo traumático de la experiencia de la guerra y compara los pozos de zorro con la vida en la calle (14). Aparecen dos internos y, tras una situación de amenaza, concluye el segundo encuentro.

La tercera unidad de fragmentación se abre con el interno justificándose. Alega que los internos le tienen envidia y lo asocia con la guerra de las Malvinas (14). La conversación pasa a la vida en las islas, el compromiso con la patria y los castigos físicos. El maltrato institucional es vinculado con la vida anterior del interno: se crio en un instituto de menores -"tengo catorce fugas" (15)-, fue abandonado por su madre y no tuvo la oportunidad de conocer a su padre. La violencia de la guerra es vinculada a la injusticia de la vida cotidiana: "la pelea era desigual (...) ¡En todas partes! En el instituto, en la calle cuando me fugaba, en el mercado donde hacía las changas... También en las Malvinas" (15). El interno vuelve a referirse a los gurkas. Tras aludir a sus heridas de batalla, revela un nuevo dato de su vida anterior: estudió hasta séptimo grado y fue adoptado durante un tiempo por una familia de Lomas de Zamora, a quienes visita durante los fines de semana. El interno se excusa y Zito Lema queda solo en el patio. Narra el violento ingreso de un "hombre vestido muy humildemente" a quien "los policías" han atado con sogas (15). El entrevistador le comenta a un enfermero, refiriéndose a los policías: "[s]on gurkas" (15; bastardillas en el original). El interno regresa y se produce un nuevo momento de puesta en incertidumbre del pacto referencial: "Veo venir al muchacho. ¿Habrá estado en las Malvinas? ¿Por qué no se lo preguntás a su médico? Sería una traición, me contesto" (15; bastardillas en el original). El joven vuelve a relatar su experiencia en los pozos de zorro y el frío y la humedad evocados lo llevan a asociar el espacio con el Hospicio de las Mercedes. Afirma que allí había un río donde se ahogaba a los locos. Se retorna al tema de las islas, hace mención a los depósitos llenos de comida y los maltratos. Luego cuenta que encontró a un gurka acostándose con un oficial y que, a partir de entonces, lo persiguen. Inmediatamente, evoca cómo asesinó a un oficial al grito de "igurka!". El motivo es la bronca ante la injusticia: "Pensé en todo eso, el viento soplaba y lo maté" (15).

Ya sea por la acentuación de la presencia subjetiva del entrevistador, la relativización del pacto referencial no-ficcional del testimonio o el carácter lírico de los parlamentos, la entrevista / artículo periodístico de Zito Lema se coloca delibe- 
radamente en una zona liminal con la poesía. Por otra parte, surge una conexión liminal entre periodismo y teatro: el diálogo y el acompañamiento de un texto segundo contextualizador pueden ser leídos como texto primero (habla de los personajes) y didascalias (acotaciones, texto secundario) de un texto teatral. Otro punto de liminalidad: teatro y periodismo comparten la observación y el registro de la realidad, poseen una matriz común en la teatralidad social, según la definición antropológica ${ }^{17}$. En este sentido, teatro y entrevista son, para Zito Lema, territorios de plena teatralidad (recuérdese el citado "Todo es teatro"), ya que poseen el potencial para desplegar ante el espectador / lector las condiciones de vida en las instituciones, la violencia social, el abandono por parte del poder ( $R$. Dubatti, 2017c). Podemos conectar esta liminalidad del periodismo con el teatro y la poesía y, por extensión, con la literatura y el arte así como con las prácticas del Nuevo Periodismo (y su correlato en la non-fiction literaria) que se imponen en la Argentina a partir de los años cincuenta y sesenta (Ford, 1972; Amar Sánchez, 1992; Rivera, 1995). Como estudiaremos enseguida, estas tensiones se relacionan principalmente con el proyecto del autor de una Antropología Teatral poética.

\section{Poética comparada y reescritura teatral}

Si se confronta "Las Malvinas en el hospicio" (1988) con Gurka (1999), se advierte que el artículo periodístico provee una base textual para la composición de la pieza teatral. Zito Lema somete el texto de la entrevista a una reescritura, entendida, según la poética comparada, como la intervención teatral (dramática y/o escénica) sobre un texto-fuente (teatral o no) previo, reconocible y declarado, elaborada con la voluntad de aprovechar la entidad poética del texto-fuente para efectuar, sobre ese texto, una deliberada política de la diferencia, de la que se genera un nuevo texto-destino (J. Dubatti, 2016). Cuando consultamos a Zito Lema sobre las operaciones de reescritura que implementó, nos señaló: "Miguel me dijo que se había metido en mi cabeza y que él me había dictado el texto. Para mí fue meterme en su cabeza" (R. Dubatti, 27 de noviembre de 2017). A su vez, en la misma entrevista, el autor nos indicó que el texto teatral fue escrito "de un tirón, sin correcciones", a la manera de "la escritura automática", sin tener delante la nota periodística, pero sí tomando en cuenta el recuerdo de las voces cruzadas de entrevistado y entrevistador.

Zito Lema realiza una reescritura compleja. En la voz del personaje de Gurka, se absorben y fusionan las de "el muchacho", la "voz que le habla" y la de Zito Lema periodista. El dramaturgo tampoco reproduce literalmente las palabras del entrevistado, sino que las recrea. Véanse a continuación tres ejemplos de reescritura:

\footnotetext{
17 "Desde una Antropología del Teatro, la teatralidad es una condición de lo humano que consiste en la capacidad del hombre de organizar la mirada del otro, de producir una óptica política o una política de la mirada. El mundo humano se sostiene en una red de mirada. Una red de mirada (de lo que debe y no debe verse, de lo que puede y no puede verse) genera acción social y sostiene el poder, el mercado, la totalidad de las prácticas sociales. (...) La teatralidad es inseparable de lo humano y acompaña al hombre desde sus orígenes" (J. Dubatti, 2016: 9).
} 


\section{“Las Malvinas en el hospicio" (1988)}

[Entrevistado] Mientras estaba en Malvinas soñaba mucho. Antes, cuando dormía en las estaciones de trenes, también. Aquí, con los medicamentos, se duerme muy profundo y el que despierta no recuerda nada.

[Entrevistador] ¿Dónde irán los sueños que uno olvida? (pregunto casi con vergüenza)

[Entrevistado] Se van al cielo. Los sueños buscan un frío como el agua, seco (12).

[Entrevistador] El viernes a la noche tuve un mal sueño. Volaba por la habitación en ligera penumbra, llena de espejos de colores opacos, como perlas sin pulir, y cada vez que cansado me detenía en el aire del interior de cualquiera de los espejos mi propia mano enguantada y con un estilete en forma de cruz me cortaba la cara (13).

[Entrevistado] Yo quiero pintar esos cuadros que tengo en la cabeza, y verlos sin que me de miedo. Yo estudié, hice hasta el séptimo grado y después fui a la escuela normal. Me había adoptado una familia de Lomas de Zamora. Los conocí pidiendo comida, estaba muy mojado. Me trataron como a un hijo. Los fines de semana los visito (15).
[Personaje] En las islas soñaba mucho. Antes, cuando dormía en las estaciones de trenes, también. Aquí, con los medicamentos, se duerme muy profundo y el que despierta tiene la cabeza pesada, una cabeza que no quiere recordar... ¿Dónde van a parar los sueños que uno olvida? La voz me dice: van al cielo; los sueños buscan un frío como el agua, seco... (14; itálica en original).

[Personaje] Esta mañana aunque había luna llena me corté el labio afeitándome. Del espejo del baño salió una mano enguantada. Tenía un cuchillo, era una cruz y me hizo un tajo. Tartamudeando me dice: con este cuchillo te te matamo, te te matamo (15; itálica en original).

[Personaje] Yo estudié, no soy un animal. ¡Yo hice el sexto grado! ¡Yo leo mucho, hasta poesía! Me había adoptado una familia dueña de una panadería. Me trataban como a un hijo. Tuve una cama con sábanas. Un lugar en la mesa. iMe gustaban tanto las medialunas! Pero estaba la hija, que andaba siempre en bombacha. ¡Fue ella la que empezó todo! ¡Sí, fuiste vos! ¡Querías bañarte conmigo! iTe reías porque el agua me tapaba! iSon todas putas! ¡Las mujeres son putas como las gallinas! iPrimero te abandonan y después quieren cogerte con la concha! Me echaron de la casa $(22)^{*}$.

* Resuenan aquí, intratextualmente, las recurrentes expresiones soeces del personaje Anahí en la pieza Locas por Gardel (1976) (Zito Lema, 2015a: 79-122) 
A diferencia del reportaje, que despliega dos voces principales (las de entrevistador y entrevistado; ésta última mediada por la del primero), el texto dramático es un monólogo / soliloquio; se concentra en la palabra de un único personaje y desaparece el entrevistador (o al menos su presencia está elidida). En el texto periodístico, las voces de ambos se van alternando y el entrevistador, Zito Lema, acompaña comentarios sobre el contexto en el que transcurre el diálogo. Sumado al registro "objetivo" del reportaje periodístico tradicional, en la nota se aporta una tensión dialógica en un triple "entre": el de la intersubjetividad del intercambio de palabras, con su mutua afectación; el de la subjetividad interior del periodista, en la que operan interpretaciones y síntesis del diálogo; el de la subjetividad del interno, en su complejidad, su dolorosa opacidad y su dificultosa accesibilidad, manifiesta parcialmente en sus palabras y sus gestos. Esta preocupación por comprender al otro, por ponerse en su lugar e identificarse con él por parte del entrevistador, aparece explicitada en la cita de Antonin Artaud incluida en la contratapa del mismo número de la revista Fin de Siglo (1988), reproducida parcialmente como epígrafe inicial del presente artículo. En su valiosa tesis Teatro, locura y sociedad en la obra dramática de Vicente Zito Lema ${ }^{18}$, Marcelo José Islas propone examinar Gurka como un monólogo (2007: 281); no se detiene a contrastar el texto dramático con el artículo de la revista Fin de Siglo y sugiere que "[e]n sus textos [los de Zito Lema] el amor está presente, pero por ausencia. La mayor parte de lo que sucede en sus obras es producto de la falta de amor. La crueldad, el abuso de poder, la violencia, la victimización de los más débiles es su resultado. En ese sentido hay una visión desesperanzada sobre el rol de la pasión en nuestra sociedad" (144). Si bien Gurka está efectivamente atravesado por la desesperanza, como afirma Islas, también se transforma en una puesta en acción del amor, en el intento de descifrar la mirada del otro, de comprenderla desde su posición. Al reducirse a una sola voz principal, al mismo tiempo se acentúa la soledad del excombatiente e interno y se potencia el sentido ético de la obra: escuchar al marginado. Zito Lema persigue la representación de un problema de la sociedad para impulsar un cambio social. Si, como observa Islas, "[e]l monólogo en teatro es la expresión de la voz de la conciencia, [porque] el conflicto está expresado consigo mismo" (146), en Gurka la híbrida fusión de las voces del entrevistador Zito Lema y del entrevistado Miguel en las palabras del muchacho es, al mismo tiempo, un vehículo de transformación. El personaje es, por un lado, un "loco de la guerra", pero también, por otro lado, quien articula una mirada más amplia, que invita a reflexionar sobre los acontecimientos y los efectos de la Guerra de las Malvinas, así como sobre su nexo con el contexto represivo de la dictadura, la violencia de la pobreza, los hospitales psiquiátricos, los reformatorios y las fuerzas de seguridad.

Deliberadamente, el texto dramático de Gurka no incluye didascalias, ni indicación alguna de quién es el personaje que habla. Toda referencia que podamos

\footnotetext{
18 Agradecemos al Dr. Nel Diago, director de tesis de Islas en la Universitat de València, el acceso a este material. Hay edición reciente de 2017.
} 
construir brota de la misma voz del personaje, y, al mismo tiempo, se relativiza por su condición de interno de un hospicio. La poética coloca al espectador en un lugar infrasciente (R. Dubatti, 2017b).

Observa Karl Jaspers (2003) que no es tanto en el contenido, como en la estructura del discurso, donde pueden observar los efectos de la esquizofrenia ${ }^{19}$. A diferencia de la pieza teatral, en el texto periodístico la interpretación de los acontecimientos se organiza desde la mirada del entrevistador. Es él quien articula la polisemia del término "gurka" y propone una síntesis de sentido. A su vez, es quien guía la mirada sobre los problemas que sufre el muchacho. La nota contrasta los desplazamientos erráticos de la locura del entrevistado con la coherencia de las preguntas y las reflexiones del entrevistador, quien incluso llega a dudar del testimonio de Miguel.

En el texto dramático, en contraste, se produce una amalgama de las voces de la nota periodística: en las palabras del muchacho se reelaboran los textos de muchacho y del entrevistador. El espectador no puede construir una lectura unívoca porque las palabras del muchacho se tornan desconfiables. Al transformarse en una voz única, se ponen de relieve las estructuras rítmicas, musicales de la poesía del autor: las repeticiones (el viento o el "frío como el agua, seco") pasan a jugar un rol clave, ya que no sólo puntúan la acción y orientan el sentido de lectura, sino que permiten generar indirectamente la síntesis simbólica que Zito Lema hace explícita en la entrevista. Gurka enlaza lo poético y lo testimonial, entre el desborde de sentido de la poesía y la referencia sociohistórica como principio estructurante. En el paso del reportaje al soliloquio/monólogo teatral, la transformación confirma la paradoja de la comunicación señalada por Yuri Lotman (1996: 50): la voz del personaje deviene más estimulante -invita a una mayor multiplicación de lecturas- mientras menos cerrada, más ambigua se presenta.

\section{La Antropología Teatral Poética: un modo integral de trabajo}

¿Qué busco con el teatro? Que ocurra la poesía. ¿Qué busco en la poesía? Que resucite la verdad de la vida. ¿Qué busco de la vida? Que el temor de la muerte no oscurezca la conciencia. Vicente Zito Lema, "Manifiesto de la Antropología Teatral Poética"

(2015b: 333)

La deliberada búsqueda de liminalidad entre periodismo, teatro y poesía -cruzadas a su vez con psicología social y política- evidenciada en las relaciones entre

\footnotetext{
19 Si bien en ningún momento se especifica que Miguel sea esquizofrénico, la comparación con los casos que releva Jaspers en su libro resulta sumamente sugestiva.
} 
"Las Malvinas en el hospicio" y Gurka responde al proyecto de Zito Lema de una Antropología Teatral Poética. En el segundo tomo de Todo es Teatro. Obra completa 1970-2015, incorpora una serie de artículos teóricos donde define la ATP como "una metodología dialéctica para la creación artística" que se define por su opuesto, "un orden social perverso" (2015b: 333). En un brevísimo paratexto de Delirium Teatro, afirma que sus instrumentos son "la conversación, con espíritu socrático; el registro de las historias de vida, con sometimiento ético; y la condensación poética. Como referencia conceptual: la lectura crítica, dialéctica de la realidad, y una visión dionisíaca del arte" (1999: 12). Apunta a rescatar

la belleza -la no bella, convulsiva y exasperada belleza- entre los pliegues más atroces y opacados de la cotidianeidad social. Su escenario es la vida y sus personajes son en su mayoría humildes criaturas que rememoran su historia sufriente, en una ceremonia de agonías -bajo la estética del auto sacramental-, con sueños y pesadillas, hasta producir la conciencia y su redención (2015b: 334).

Más adelante, agrega que "no descansa en la ficción, se mueve en la exasperante realidad de lo real" (335). La ATP parte de un acontecimiento social que impacta al autor. En este aspecto, los sueños también son incluidos, debido a que poseen efectos en la vida cotidiana y son parte de la vida psicológica y social de cada persona. Siguiendo a Enrique Pichon-Rivière, el objetivo es "la conversión de lo siniestro en lo maravilloso" (336), es decir, tomar conciencia de las injusticias sociales y modificar la realidad, intervenir en la vida cotidiana, "subvertir el orden del poder, el orden de la no justicia -más aún: destruir su estructura-, para que brille la vida" (336).

A partir del relevamiento de un hecho social que impacta al artista, este debe realizar una "pesquisa" (337), una investigación cuyo resultado es un primer texto donde se busca relevar "la esencia" (336) de ese acontecimiento mediante el procedimiento de la condensación poética. En este primer texto, de estructura dramática, se incorporan todos los elementos que aparezcan como relevantes para la creación artística: testimonios, reportajes, canciones, etc. Se trata de un modo de trabajo que abraza lo liminal. "El círculo se completa con la creación, publicación y difusión de un libro (o cosa semejante), que recoja el material gestado, sin perjuicio de aplicar otra vez los mecanismos de la condensación poética" (338; bastardilla en el original). Esta editorialización responde a la construcción de un objeto artístico que pueda ser ofrecido a la sociedad.

Zito Lema privilegia al teatro como territorio de editorialización debido a su carácter de ritual compartido por una comunidad. Su concepción del teatro y del arte se encuentra arraigada en la tragedia clásica griega. El autor considera no sólo la importancia del teatro como ritual, sino que también entiende como fundamentales la mímesis idealizante de la violencia, la catarsis, el distanciamiento teatralista (o convención consciente), lo coral, las máscaras. A su vez, concuerda con la perspectiva del teatro griego como mirador de los conflictos entre el hombre y la sociedad (Kaufmann, 1978) y, por tanto, como zona de interrogación sobre 
la existencia humana. A esto se suma una perspectiva platónica del mundo, donde la verdad y la belleza se encuentran conectadas por un principio ético. Retratar lo real es un compromiso no sólo con aquellos a quienes se ofrece el "libro", sino también con aquel hecho social del que se parte. Zito Lema cita a Jacobo Fijman para expresar su pensamiento: "Hemos entrado en la piel del otro, sea por la fe o sea por la poesía" (336). El libro se dirige al espectador para que este pueda realizar sus propias lecturas sobre los hechos. En este aspecto, el teatro de Zito Lema es simultáneamente un teatro tautológico y un teatro estímulo: encarna y defiende ideas anteriores al acontecimiento poético -"la creencia de que el bien siempre será bello, aunque la belleza more hoy en los desiertos espinosos de la pobreza y el bien apenas pueda ser escuchado desde el silencio que impone el lenguaje del mal" (340; énfasis en el original)-, pero lo hace apelando al ángulo voluntario / espectatorial, buscando multiplicar las miradas sobre el hecho social. La ATP es a su vez una manifestación ética desde una perspectiva política. Como disciplina que trabaja con la teatralidad antropológica, siempre apunta a una modificación de la vida cotidiana. Al mismo tiempo, involucra la responsabilidad del artista, ya que debe ejercer de manera pertinente su rol. Debe siempre operar a la manera en que Edward Said (1996) concibe al intelectual, es decir, como una figura en constante desplazamiento, obligada por su propia labor a ser crítica e inconformista, a tomar distancia del poder como ente normalizador o regulador. Como explicita el propio Zito Lema en una entrevista realizada por Conrado Yasenza:

El asumir socialmente el rol del intelectual descansa en un privilegio, que a su vez descansa en un orden de producción. Desde mi concepción ética, tener conciencia de ese privilegio, y a la vez, conocer el dolor que produce la exclusión de grandes mayorías sociales, deriva en que me convierta en un ser que quiere abolir el propio orden social que me convierte en intelectual; y por ello, soy un traidor del sistema, o para el sistema. Creo que esta es la única forma en que un intelectual puede vivir en la contradicción: cuando tiene conciencia del privilegio del que goza, y cuando tiene plena conciencia de que ese privilegio se funda en el dolor del otro ( 8 de junio de 2006).

En "A manera de prólogo. Radiografía del hospicio", incluido en Delirium Teatro (1999: 5-10), el autor observa que "[a]unque la sociedad le retacee su condición humana (...), el loco del hospicio seguirá con su sufrimiento alertándonos que es posible acceder a una verdad demistificada" (1999: 10). La locura aparece como una forma de pensamiento ex-céntrico, corrido de lo que institucionalmente se considera como "correcto".

En conclusión, a partir del modo de trabajo particular que posibilita la ATP, se configura una escritura abierta a la liminalidad y a la teatralidad antropológica. La poética de Gurka se revela plenamente cuando se la considera como una red de interconexiones de diversos aspectos de las prácticas sociales (periodismo, psicología social, política, teatro, poesía, antropología...). Una poética de tensiones liminales. El de Zito Lema es un teatro del borde o de los bordes, entendidos como zonas de frontera o tierras de nadie, de desdibujamiento de los límites precisos 
y del alejamiento de los centros del poder. Lo es doblemente, pues va a los bordes sociales para darles voz a quienes no tienen visibilidad en una sociedad violentamente racionalista y utilitaria y también persigue una poética que, en tanto metáfora epistemológica (Eco, 1984: 88-89), encarna estructural, formalmente la problemática de la liminalidad. En suma, se trata de una dramática de liminalidades para un teatro de los bordes sociales.

\section{Referencias}

Agamben, G. (2000). Lo que queda de Auschwitz. Homo Sacer III. Valencia: PreTextos.

Amar Sánchez, A. M. (1992). El relato de los hechos. Rodolfo Walsh: testimonio y escritura. Rosario: Beatriz Viterbo.

Artaud, A. (1988). Carta a los directores de los asilos de locos. Fin de Siglo, (10), abril, contratapa.

Bourriaud, N. (2009). Radicante. Buenos Aires: Adriana Hidalgo.

Cattaruzza, A. (2012). Dimensiones políticas y cuestiones historiográficas en las investigaciones históricas sobre la memoria. Storiografía, (16), 71-91.

Chartier, R. (1992). El mundo como representación. Estudios sobre historia cultural. Barcelona: Gedisa.

Diéguez Caballero, I. (2007). Escenarios Liminales. Teatralidades, performances y política. Buenos Aires: Atuel.

Dubatti, J. (2016). Teatro-matriz, teatro liminal. Estudios de Filosofía del Teatro y Poética Comparada. Buenos Aires: Atuel.

(2012). Cien años de Teatro Argentino. Desde 1910 a nuestros días. Buenos Aires: Biblos.

(2009). Concepciones de teatro. Poéticas teatrales y bases epistemológicas. Buenos Aires: Colihue.

Dubatti, R. (2017a). Prólogo. La guerra en el teatro, el teatro de la guerra. En Dubatti, R. (comp.), Malvinas. La guerra en el teatro, el teatro de la guerra. Buenos Aires: Centro Cultural de la Cooperación, 7-26.

(2017b). Gurka (un frío como el agua, seco), de Vicente Zito Lema: delirio, confinamiento y represión social institucionalizada. En Mirza, R. (ed.). Crisis de la dramaturgia y de las prácticas escénicas en la contemporaneidad. Montevideo: Universidad de la República, 123-138.

(2017c). Liminalidad entre periodismo y teatro: entrevista / dramaturgia (en torno a la Guerra de Malvinas). En AA.VV., Poéticas de liminalidad en el teatro. Lima: Escuela Nacional Superior de Artes Dramáticas (ENSAD), 300-310. 
(27 de noviembre de 2017). Entrevista con Vicente Zito Lema. Inédita.

Eco, U. (1984). Obra abierta. Barcelona: Ariel.

Ford, A. (1972). Literatura, crónica y periodismo. Las literaturas marginales. Buenos Aires: Centro Editor de América Latina, 97-120.

Grésillon, A. (1994). Eléments de critique génétique. Lire les manuscrits modernes. París: PUF.

Guillén, C. (1985). Entre lo uno y lo diverso. Introducción a la literatura comparada. Barcelona: Crítica.

Islas, M. J. (2007). Teatro, locura y sociedad en la obra dramática de Vicente Zito Lema. Tesis de doctorado, Departament de Filología Espanyola, Universitat de Valencia.

Jaspers, K. (2003). Genio artístico y locura. Strindberg y Van Gogh. Madrid: El acantilado.

Jelin, E. (2002). Los trabajos de la memoria. Madrid: Siglo XXI.

Kaufmann, W. (1978). Tragedia y filosofía. Madrid: Seix Barral.

Kon, D. (1982). Los chicos de la guerra. Hablan los soldados que estuvieron en Malvinas. Buenos Aires: Galerna.

Lois, É. (2001). Génesis de escritura y estudios culturales. Introducción a la crítica genética. Buenos Aires: Edicial.

Lotman, Y. (1996). La semiosfera I. Semiótica de la cultura y del texto. Valencia: Frónesis Cátedra.

Mancuso, H. (2010). De lo decible. Entre semiótica y filosofía: Peirce, Gramsci, Wittgenstein. Buenos Aires: SB.

Martínez Fernández, J. E. (2001). La intertextualidad literaria (Base teórica y práctica textual). Madrid: Cátedra.

McGuirk, B. (2007). Falklands Malvinas. An unfinished business. Seattle: New Ventures.

Rivera, J. B. (1995). El periodismo cultural. Buenos Aires: Paidós.

Rozitchner, L. (2015). Malvinas: de la guerra sucia a la guerra limpia. Buenos Aires: Biblioteca Nacional.

Said, E. (1996). Representaciones del intelectual. Barcelona: Paidós.

Weil, S. (1961). La llíada o un poema de la fuerza. La fuente griega. Buenos Aires: Sudamericana, 13-44.

Yasenza, C. (8 de junio de 2006). La piel del Otro. ElBarullo de Conrado Yasenza (sitio web). Recuperado de http://elbarullo.wixsite.com/el-barullo-de-conrado-yasenza/vicente-zito-lema-la-piel-del-otro.

Zito Lema, V. (2015a). Todo es teatro. Obra completa 1970-2015. Tomos I. Río Cuarto: UniRío. 
(2015b). Todo es teatro. Obra completa 1970-2015. Tomos II. Río Cuarto: UniRío.

(2000). Lengua sucia. Escenas de poder, servidumbres y muertes. Buenos Aires: Fin de Siglo.

(1999). Radiografía del hospicio, Notas sobre el trabajo y Gurka (un frío como el agua, seco). Delirium Teatro. La Plata: De la Campana, 5-24. (1988). Las Malvinas en el hospicio. "Un frío como el agua, seco". Fin de Siglo, (10), abril, 12-15. 